\title{
The impacts of cypermethrin pesticide application on the non-target microbial community of the pepper plant phyllosphere
}

\author{
Baoguo Zhang ${ }^{a}$, Zhihui Bai ${ }^{a, *}$, Daniel Hoefel ${ }^{b}$, Ling Tang ${ }^{a}$, Xiaoyi Wang ${ }^{c}$, Baoju Li ${ }^{d}$, \\ Zuming $\mathrm{Li}^{e}$, Guoqiang Zhuang ${ }^{a}$ \\ ${ }^{a}$ Research Centre for Eco-Environmental Sciences, Chinese Academy of Sciences, Beijing 100085, China \\ ${ }^{\mathrm{b}}$ Australian Water Quality Centre, South Australian Water Corporation, Bolivar, SA 5110, Australia \\ ${ }^{\mathrm{c} E n t o m o l o g y, ~ C o m m o n w e a l t h ~ S c i e n t i f i c ~ a n d ~ I n d u s t r i a l ~ R e s e a r c h ~ O r g a n i z a t i o n, ~ B l a c k ~ M o u n t a i n, ~ A C T ~ 2601, ~ A u s t r a l i a ~}$ \\ ${ }^{d}$ Institute of Vegetables and Flowers, Chinese Academy of Agricultural Sciences, Beijing 100081, China \\ 'Teacher's College of Beijing Union University, Beijing 100011, China
}

\section{A R T I C L E D A T A}

Article history:

Received 24 July 2008

Received in revised form

21 November 2008

Accepted 21 November 2008

Available online 9 January 2009

Keywords:

Cypermethrin

Phyllosphere

Microbial community

PLFA

DGGE

\begin{abstract}
A B S T R A C T
Although pesticides have been extensively used for controlling insects and disease pathogens of plants, little is known regarding the impacts of applying these pesticides on the microbial community in the plant phyllosphere. Here, we report the effects of cypermethrin pesticide application upon the microbial community of the pepper plant phyllosphere. Assessments were made using culture-independent techniques including phospholipid fatty acid analysis (PLFA) and 16S rRNA gene directed Polymerase Chain Reaction with Denaturing Gradient Gel Electrophoresis (PCR-DGGE). During the 21 day greenhouse study, PLFA results indicated that both total and bacterial biomass increased after application of the pesticide. PLFA profiles also indicated that Gram-negative bacteria became predominant. DGGE analysis confirmed a significant change in bacterial community structure within the phyllosphere following the pesticide application where different dendrogram clusters were observed between control and treated samples. Phylogenetic analysis also suggested a change in bacterial phyla following treatment, where bands sequenced within control cultures were predominantly of the Firmicutes phylum, but those bands sequenced in the treated samples were predominantly members of the Bacteroidetes and $\gamma$-Proteobacteria phyla. In conclusion, this study revealed an increase in bacterial abundance and a shift in community composition within the pepper plant phyllosphere following the pesticide application, and highlighted the effective use of PLFA and PCR-DGGE for studying the effect of pesticides upon indigenous phyllosphere microbes.
\end{abstract}

(c) 2008 Elsevier B.V. All rights reserved.

\section{Introduction}

The indigenous microbial communities that reside within the phyllosphere are highly diverse and include many different species of bacteria, filamentous fungi, yeasts and algae (Lindow and Brandl, 2003). The community composition of phyllosphere microbes are affected by many different factors including plant species, fluctuations in ambient temperature, changes to relative humidity, nutrient availability upon the plant surface and direct solar UV radiation (Lindow and Leveau, 2002). Phyllosphere microbes often have a direct positive influence in altering plant surface properties, where

\footnotetext{
* Corresponding author. 18 Shuangqing Road, Haidian District, Beijing 100085, China. Tel.: +8610 62923562; fax: +861062923563.

E-mail address: zhbai@rcees.ac.cn (Z. Bai).
} 
they may be involved in the fixation of nitrogen, promoting the growth of plants, the control of plant pathogens, or the degradation of organic pollutants (Kvasnikov et al., 1974; Murty, 1984; Hirano and Upper, 2000; Krechel et al., 2002; Krimm et al., 2005; Schreiber et al., 2005; Sandhu et al., 2007). However, some phyllosphere microbes have negative effects upon the host where plant pathogens may result in disease. In addition, if proper farming practices are not followed, phyllosphere microbes may include human pathogens, thus compromising the safety of plant food grown for consumption (Henis and Bashan, 1986; Lindow and Leveau, 2002).

Pesticides have become an important tool for crop protection due to their ability to control unwanted insects and microbial pathogens. However, many pesticides are nonspecific in their mode of action, resulting in changes to the composition of non-target microorganisms within the phyllosphere, including those that may have been of benefit to the plant. The effects of a particular pesticide on phyllosphere microbes are dependent upon the specific chemical properties of the pesticide (including any associated emulsifiers or other chemicals if the pesticide is mixed prior to application), the concentration at which the pesticide is used, the types of indigenous phyllosphere microorganisms present, and the environment in which the microorganisms are growing (Lal and Saxena, 1982). The application of pesticides may decrease the microbial biomass due to the direct toxicity of the pesticide (Ko and Lockwood, 1968), or in some cases increase the microbial biomass because of the pesticide (and other associated emulsifiers or solvents) supplying a nutrient source (Chinalia and Killham, 2006), in addition to changes due to indirect ecological effects such as the death of microbial predators, or in some cases there may be no effect at all (Pandey and Chauhan, 2007). Many studies have been performed to assess the effects of pesticides on microbial communities from a range of environments (Salonlus, 1972; Vig et al., 2008; Walter et al., 2007).

Pepper (Capsicum annuum L.) is one of the most popular vegetables consumed by the Chinese people. During its cultivation, the vegetable is often damaged by insects such as Pieris rapae L., Plutella xylostella L., Helicoverpaassulta Guenee, Spodoptera litura F., Lipaphis erysimi, Aphis gossypii, and Myzus persicae. Various pesticides (including chlorpyrifos, cypermethrin, fenproparthrin, deltamethrin, pirimicarb, cyhalothrin and esfenvalerate) are often used to control these insects. To date, the toxic effects of these pesticides on indigenous pepper phyllosphere microorganisms have only been assessed using individual indicator microorganisms and their survival assessed using traditional culture-dependent methods (Russell et al., 1999). Tests which examine the fate of an individual species fail to assess more subtle changes to the composition of phyllosphere communities in response to pesticide exposure. Moreover, traditional culture-dependent techniques are of limited use for the analysis of microbial assemblages, since more than $90 \%$ of indigenous microorganisms in nature are not culturable under laboratory conditions (Amann et al., 1995). In recent years, various culture-independent methods such as phospholipid fatty acid analysis (PLFA) and 16S rRNA gene directed Polymerase Chain Reaction-Denaturing Gradient Gel Electrophoresis (PCR-DGGE) have been useful for detecting pollutant-induced changes in the composition of natural microbial communities (Morimoto et al., 2005; Chinalia and Killham, 2006; Ratcliff et al., 2006). PLFA results are interpreted based on the assumption that phospholipids make up a relatively constant proportion of the cell biomass and that variation in fatty acids among taxonomic groups can be used as biomarkers and the PLFA pattern of an environmental sample therefore reflects the microbial community composition (White et al., 1996; Zhang et al., 2008). PCR-DGGE separates 16S rRNA gene fragments based on differences to their resistance to chemical denaturation, generating a genetic profile of the individual bacterial species within a community (Burr et al., 2006; Zhang et al., 2008). Applying such culture-independent methods to ecotoxicology studies may provide new insights into the pesticide-induced changes that occur to indigenous microbial communities of plants.

Using PLFA and PCR-DGGE, this study investigated whether cypermethrin pesticide application to pepper plant cultivars resulted in significant changes to the microbial community within phyllosphere.

\section{Materials and methods}

\subsection{Growth of pepper plants}

The experiments were conducted in a greenhouse located within the Institute of Vegetables and Flowers, Chinese Academy of Agriculture Sciences, China. 360 pepper plants (C. annuum L.) were planted in $120 \mathrm{~m}^{2}$ plots in a greenhouse on 13 March 2006. During the growth of the plants, the average daily air temperature ranged from 18 to $27{ }^{\circ} \mathrm{C}$, the average relative air humidity was $65 \%$, and the light intensity was approximately 20,000-40,000 lx in the greenhouse. Plants were watered and fertilized in accordance to local grower practices. When the diameter of pepper fruit reached 1-2 cm, 180 plants were sprayed with a single treatment of $6 \mathrm{ml}$ cypermethrin emulsifiable concentrate (EC, cypermethrin 4.5\%, w/w, $8 \%$ agricultural emulsifier No. 600 and $87 \%$ dimethylbenzene), which had been diluted with water (EC: water=1:1000), in accordance to the recommended dosage for pepper cultivars. The expected half-life of cypermethrin was about 6 days at the light conditions in the greenhouse. Another 180 pepper plants were sprayed with water as control. Fifty g of wet-leaf material was collected from each control and treatment samples at 1, 3, 5, 9, 14 and 21 day after treatment. Three replications of each sample were included. Immediately after sampling, the leaves were placed into sterile polythene bags and transported to the laboratory at $4{ }^{\circ} \mathrm{C}$ and processed immediately for PLFA analysis. Leaves used for DNA extraction and subsequent 16S rRNA gene directed PCR-DGGE were stored at $4{ }^{\circ} \mathrm{C}$ until required.

\subsection{Detachment of phyllosphere microbes}

For each sample and control, $10 \mathrm{~g}$ of leaf material was aseptically transferred into polypropylene tubes containing $100 \mathrm{ml}$ washing solution (0.1 M potassium phosphate buffer, $\mathrm{pH}$ 7.0). Sonication was then performed at a frequency of $40 \mathrm{kHz}$ for $7 \mathrm{~min}$ in an ultrasonic cleaning bath (Shanghai Kudos Instrument Co.) to dislodge the microbes from leaf 
surface. Leaf debris was then removed by slow speed centrifugation (TGL-20M, XiangYi Centrifuge Instrument Co., Ltd.) at $500 \times \mathrm{g}$ for $15 \mathrm{~min}$ at $4{ }^{\circ} \mathrm{C}$, and the microbes within the supernatant aspired. The suspension underwent an additional round of centrifugation at $7000 \times \mathrm{g}$ for $15 \mathrm{~min}$ at $4{ }^{\circ} \mathrm{C}$ and the microbes in the pellet were used for phospholipid fatty acid extraction. For PCR-DGGE analysis, a separate $10 \mathrm{~g}$ of leaf material was treated as described above, followed by resuspension of the microbes pellet in $7 \mathrm{ml}$ of washing solution and centrifugation at $7000 \times \mathrm{g}$ for $15 \mathrm{~min}$ at $4{ }^{\circ} \mathrm{C}$ again. The supernatant was aspired and the microbes within the pellet were used for DNA extraction prior to PCR-DGGE analysis.

\subsection{Phospholipid fatty acid (PLFA) analyses}

Triplicate control and cypermethrin treatment samples, that had been grown for 1, 3, 5, 9, 14, and 21 days following pesticide application, were used for PLFA analysis. Fatty acids were extracted using a modified procedure described by Pennanen et al. (1999). Briefly, the microbial pellet that had been obtained from $10 \mathrm{~g}$ of pepper leaves was transferred to a glass tube with a Teflon-lined screw cap. Lipids were extracted from the microbial pellet obtained from the leave-samples by a one-phase chloroform, methanol and $0.15 \mathrm{M}$ citrate buffer extractant solution. The total lipid extract was then fractioned into neutral, glyco- and polar (phospho-) lipids by silicic acid chromatography. Polar phospholipids were then converted to fatty acid methyl esters using a mild alkaline methanolysis reaction. An internal standard, methyl ester of nonadecanoic acid (19:0) was added and these dissolved in hexane for chromatographic analysis. Fatty acid methyl esters (FAMEs) were analyzed by a GC-MS system (Hewlett Packard HP 6890) equipped with a HP-5 capillary column $(60 \mathrm{~m} \times 0.32 \mathrm{~mm})$. Total quantity (nmol $\mathrm{g}^{-1}$ ) was assessed using the methyl ester of nonadecanoic acid as an internal standard.

PLFAs were defined by standard nomenclature: the total number of carbon atoms, followed by a colon, and the number of double bonds. The position of the first double bond is indicated by " $\omega$ " followed by the number of carbon atoms counted from the aliphatic end. The suffixes $c$ for cis and $t$ for trans refer to geometric isomers. The prefixes "a" and "i" refer to anteiso- and iso-branched fatty acids. The prefix "10Me" indicates a methyl group on the tenth carbon atom from the carboxyl end of the molecule. The prefix "cy" denotes cyclopropane fatty acids. To estimate the various proportions of the main taxa in samples by PLFAs, biomarkers a15:0, i15:0, i16:0, i17:0 and a17:0 were used to represent Gram-positive

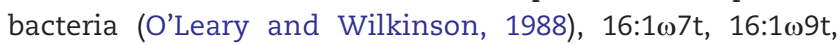
cy17:0, 18:1 17 and cy19:0 to represent Gram-negative bacteria

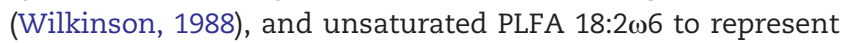
fungal biomass (Johansen and Olsson, 2005; Patra et al., 2008).

\subsection{PCR-DGGE analysis of 16S rRNA gene fragments}

DNA from phyllosphere microbes of both controls and cypermethrin treated leaves was extracted using the method described by Yang et al. (2001), and subsequently purified using the DNA Gel Recovery Kit (Omega Bio-tek, Inc.) following the manufacturer's instructions. The highly variable V3 region of the 16S rRNA gene was then amplified by PCR using the primer set GC-PRBA338f and PRUN518r (Øvreås et al., 1997). The GC-clamp was attached to the PRBA338f primer to enhance the separation of the DNA fragments on the DGGE gel. The PCR mix $(50 \mu \mathrm{L})$ consisted of $1 \times$ PCR buffer, $2.5 \mathrm{mM}$ $\mathrm{MgCl}_{2}, 200 \mu \mathrm{M}$ of each dNTP, $20 \mathrm{pmol}$ of each primer, 2.5 units of TaKaRa Taq DNA polymerase and $10 \mathrm{ng}$ genomic DNA. PCR conditions were $92{ }^{\circ} \mathrm{C}$ for $4 \mathrm{~min}$, followed by 30 cycles of $92^{\circ} \mathrm{C}$ for $1 \mathrm{~min}, 55^{\circ} \mathrm{C}$ for $30 \mathrm{~s}$, and $72^{\circ} \mathrm{C}$ for $1 \mathrm{~min}$ followed by a final extension at $72{ }^{\circ} \mathrm{C}$ for $10 \mathrm{~min}$.

DGGE was performed with the Dcode ${ }^{\mathrm{TM}}$ universal mutation detection system (Bio-Rad). PCR products $(20-25 \mu \mathrm{L})$ were loaded onto $10 \%$ (w/v) acrylamide:bisacrylamide (37.5:1, m:m) gel containing a 20 to $60 \%$ linear gradient of formamide and urea (100\% denaturing solution contained $40 \%$ formamide and $7 \mathrm{M}$ urea). The gel was run for $10 \mathrm{~h}$ at $60^{\circ} \mathrm{C}$ with $100 \mathrm{~V}$ in $1 \times \mathrm{TAE}$ buffer. After electrophoresis, the gel was stained with $0.5 \mu \mathrm{g} / \mathrm{ml}$ ethidium bromide (Sigma) and photographed with a Fluor-S Multi Imager system (Bio-Rad).

\subsection{Sequence analyses}

DGGE bands of interest were excised from the gel using a sterile scalpel, and the DNA subsequently eluted overnight at $37{ }^{\circ} \mathrm{C}$ in sterile distilled water. Excised DNA was then reamplified using the primer pair PRBA 338f and PRUN518r as described previously. The resulting PCR products were cloned into the pGEM-T Easy vector (Promega, Germany) and then transformed into competent DH5 $\alpha$ cells. The about $200 \mathrm{bp}$ rRNA gene fragment inserts were then sequenced from T7 primer sites on the vector. Sequence homology searches were performed at the National Centre for Biotechnology Information using the BLAST network service (BLASTN). Multiple alignments and distance matrix analyses were conducted using the MEGA 3.0 software package (Kumar et al., 2004). A phylogenetic tree was constructed using neighbor-joining analysis with 1000 replicates of bootstrap analysis. Sequence data obtained in this study was deposited in the GenBank database under accession numbers EU200325-EU200346.

\subsection{Statistical analysis of PLFA profiles and DGGE bands}

Fatty acids with carbon lengths of 14 to 22 were used to analyze the microbial community structure of the phyllosphere. Data were presented as means together with standard deviations (SDs). For PLFA concentrations, the ratios of the different microbial groups, in addition to the Gram-positive bacteria (GP):Gram-negative bacteria (GN) ratio, were analyzed using analysis of variance (ANOVA) with SPSS software (version 13.0, SPSS Inc.). Principal-component analyses (PCA) were performed to compare the PLFA profiles in the samples. This was performed on $\log _{10}$ transformed mole percentages of individual PLFAs. The mole percentages distribution of PLFAs was analyzed using one-way ANOVA with the least significant difference (LSD). The results were accepted as significant at $\mathrm{P}<0.05$.

The profiles of DGGE were analyzed using Quantity One-4.6 software (Bio-Rad) to calculate bacterial community similarity values. Based on band presence/absence and band weighting (band density) analysis, a dendrogram was constructed using the DICE coefficient and the unweighted pair group method 

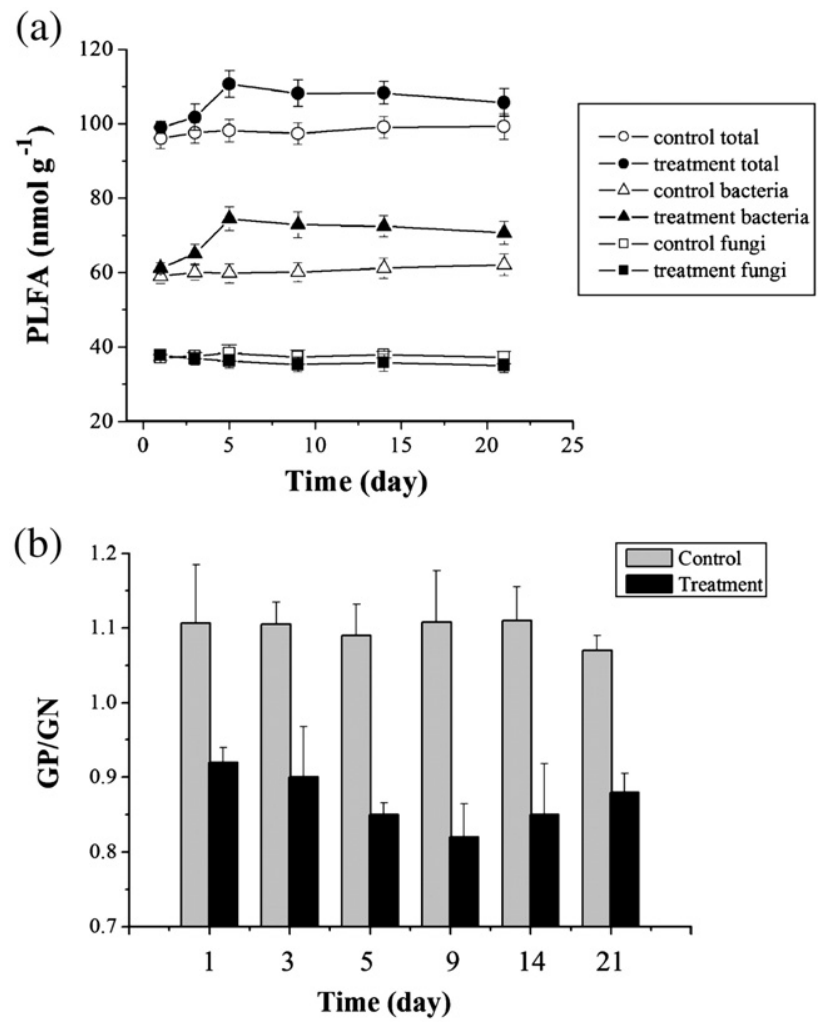

Fig. 1-Response of pepper phyllosphere microbes during the 21 days following cypermethrin pesticide treatment. (a) total PLFA, bacteria PLFA and fungal PLFA; (b) GP/GN PLFA profiles. Bars represent the SDs of the means $(n=3)$.

using arithmetic averages (UPGMA). Cluster analysis was performed with the SPSS software (version 13.0, SPSS Inc.). In order to investigate statistical significance, we used the Monte Carlo permutation test based on 499 random permutations and a significance level of $P<0.05$, assuming the null hypothesis that microbial community were unrelated to cypermethrin pesticide application.

\section{Results}

\subsection{PLFA analyses}

The total abundance of PLFAs can be directly related to the total microbial biomass within the phyllosphere of the pepper plants tested in this study. PLFA profiles revealed a significant effect of cypermethrin pesticide application on the pepper plant phyllosphere microorganisms (Fig. 1). During the 21 days study, both the total PLFAs and bacterial PLFAs were significantly higher $(P<0.05)$ for the cypermethrin pesticide treated samples when compared to the controls (Fig. 1a). Both the total PLFAs and bacterial PLFAs concentrations peaked 5 days after application of the pesticide and then declined slightly for the remaining 16 days of the study. During the 21 days, the PLFA of the microorganisms within the control phyllosphere remained relatively stable. In contrast, the PLFA associated with fungal biomass within the pesticide treated phyllosphere was significantly lower $(P<0.05)$ and decreased over the first 5 days after treatment, compared to the control (Fig. 1a). After this time, the PLFAs of the pesticide treated and control followed the same trend. The ratio of Gram-positive bacteria (GP) to Gram-negative bacteria (GN) was also significantly affected by cypermethrin pesticide treatment $(P<0.05)$, where this ratio decreased significantly over the first five days, and was consistently lower than the associated control (Fig. 1b). As the concentration of Gram-negative bacterial PLFA was higher than that of Gram-positive bacteria PLFA in the pesticide treated phyllosphere, cypermethrin pesticide application appeared to result in an increased abundance of Gram-negative bacteria within the pepper phyllosphere.

The distribution of the control/treatments in the score plots of the first two principal components (PCs) of PLFAs indicated that cypermethrin pesticide application affected the microbial community structure of the phyllosphere, where

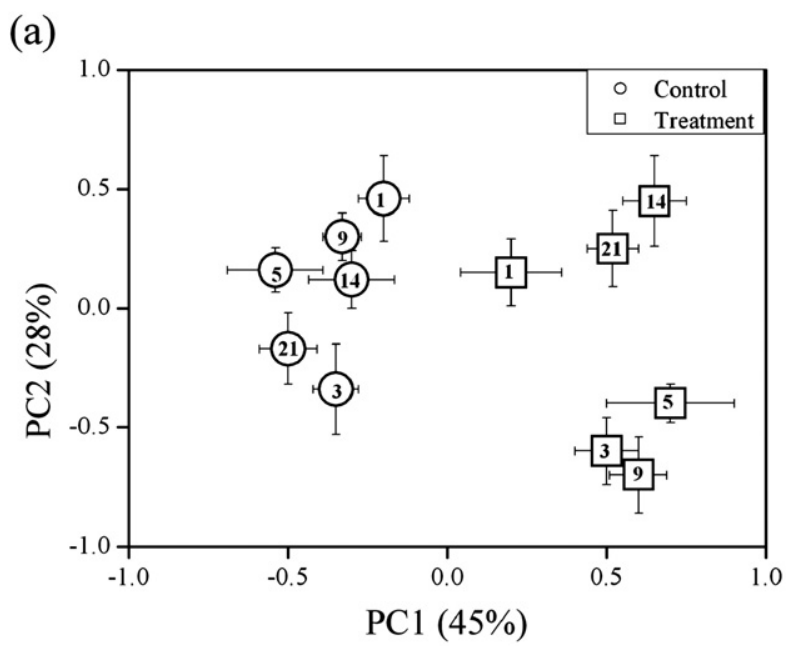

(b)

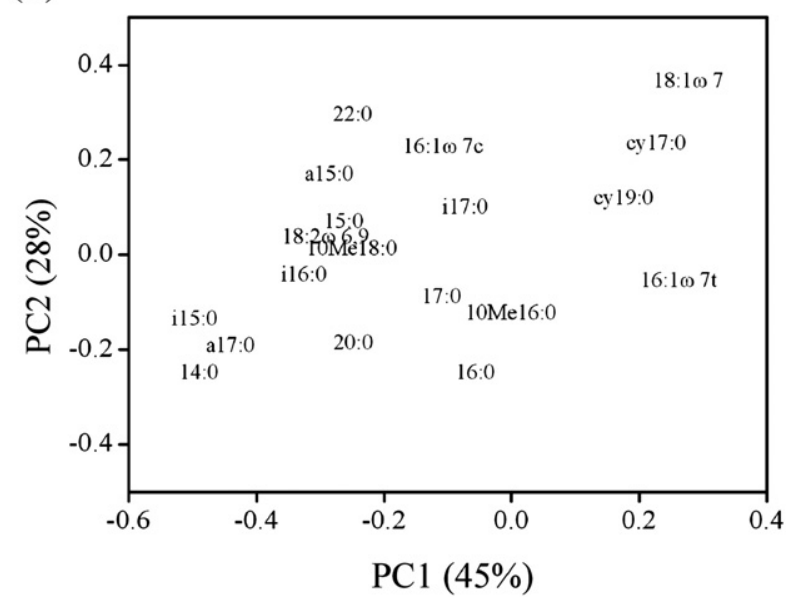

Fig. 2-Scatter plot of the (a) score and (b) loading values of the first two principal components in a principal component analysis of relative molar abundance of fatty acids originating from the phospholipids in the total microbial community in pepper cultivar phyllosphere. The day after treatment is shown by the individual marker. Bars represent the SDs of the means $(n=3)$. 


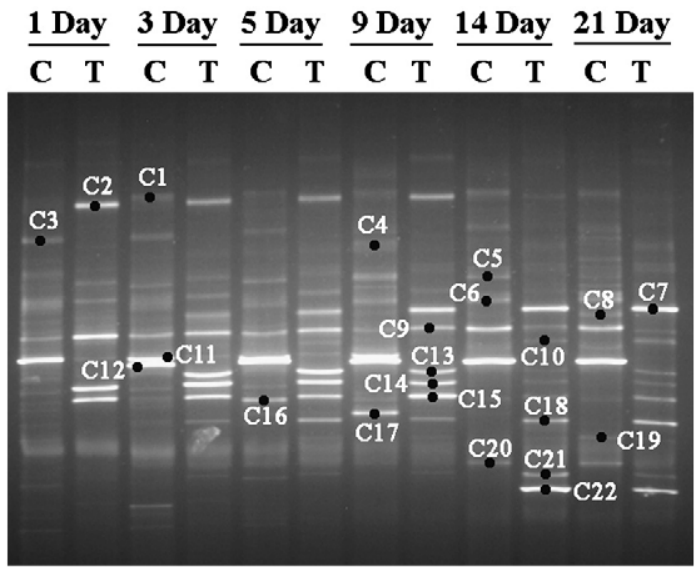

Fig. 3 - Denaturing Gradient Gel Electrophoresis (DGGE) profile for PCR-amplified fragments of the 16S rRNA gene for (C) control and (T) treated samples from (D1) day 1 to (D21) day 21 following cypermethrin pesticide treatment.

PC1 and PC2 account for $45 \%$ and $28 \%$ of the variation, respectively (Fig. 2). PLFA patterns from the pesticide treatment plots were clearly different from that of control plots and scores from the treatment coordinated to the right in the score plot along PC1, while the controls were located to the left (Fig. 2a). The treatment at different times were similar along PC1, but showed some variation along PC2. Hence, succession time (represented by PC2) was another factor responsible for the variation in the pesticide treated phyllosphere microbial community. The PLFAs responsible for the separation in the $\mathrm{PC}$ are shown in Fig. 2b. By their loading values it is evident

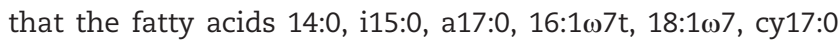
and cy19:0 were most important for the separation of the pesticide treatment samples. The loadings showed that PC1 had a clear positive relationship with the following four PLFA

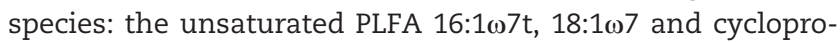
pane cy17:0, cy19:0 (indicator of Gram-negative bacteria). These PLFA species were found in the right part of the loading plot, indicating that these PLFAs tended to increase under the pesticide treatment. On the other hand, the saturated PLFA 14:0, i15:0 and a17:0 (indicator of Gram-positive bacteria) were identified as being negatively correlated with PC1, indicating that these PLFAs tended to decrease under the pesticide treatment. PLFA found in the mid-section of PC1 were not affect by cypermethrin pesticide application.

\subsection{DGGE analysis}

DGGE analysis of 16S rRNA gene fragments was used to examine the effects of cypermethrin pesticide application upon the phyllosphere microbial communities at the molecular level (Fig. 3). DGGE profiles of the pesticide treated samples differed from the control, with the appearance of several new bands following treatment (bands C2, C14, C15) or the disappearance of bands following cypermethrin pesticide application (bands C1, C3, C4, C6, C11, C12). In some instances, there was also an increase in the relative intensities of existing bands (bands C9, C13) after the treatment. The effect of cypermethrin pesticide treatment upon the phyllosphere community was further confirmed by Monte Carlo permutation test (data not shown), where DGGE profiles from treatment samples were significantly different $(P<0.05)$ from those of control samples.

DGGE analysis of the control samples revealed relatively persistent banding profiles over the course of this study. Only minor changes in bands were observed and one example included band C17, which was detected at day 5, and subsequently increased in relative intensity at day 9, but disappeared at day 14 . The high degree of similarity between band profiles of the control samples over the course of this study was further demonstrated in the dendrogram analysis (Fig. 4), where a similarity coefficient of greater than $90 \%$ was observed before any branching between sample days.

Nine bands were detected in DGGE profiles from cypermethrin pesticide treated samples but were not detected in the control samples. Bands C2, C14, and C15 were detected in all of the treated samples, but the relative intensities of those bands appeared to decrease from day 14 onwards. Bands C7 and C18 become observable at day 3 and then increased in relative intensity until day 21. Band C13 also appeared at day 3, but its relative intensity then decreased. Bands C21 and C22 only appeared at day 14 and then became less intense at day 21, whereas C10 appeared at day 14 but increased slightly in intensity at day 21 . Overall, the differences between samples following application was more pronounced than for the control samples. This was shown in the dendrogram analysis (Fig. 4) where a similarity coefficient of $78 \%$ was observed before branching of samples occurred. Within the samples, days 1, 3, 5 and 9 clustered together, but a significant difference was observed following day 1 as this sample formed a sub cluster alone. The major change following the pesticide treatment appeared to occur at day 14 onwards, with samples of day 14 and 21 clustering separately from the other treated samples.

Results of the sequence homology searches for the 22 bands labeled in Fig. 3 are presented in Table 1. Their phylogenetic relationship to other closely related species is shown in the neighbor-joining tree in Fig. 5. Results of this study showed that the sequences belonged to members of the Firmicutes,

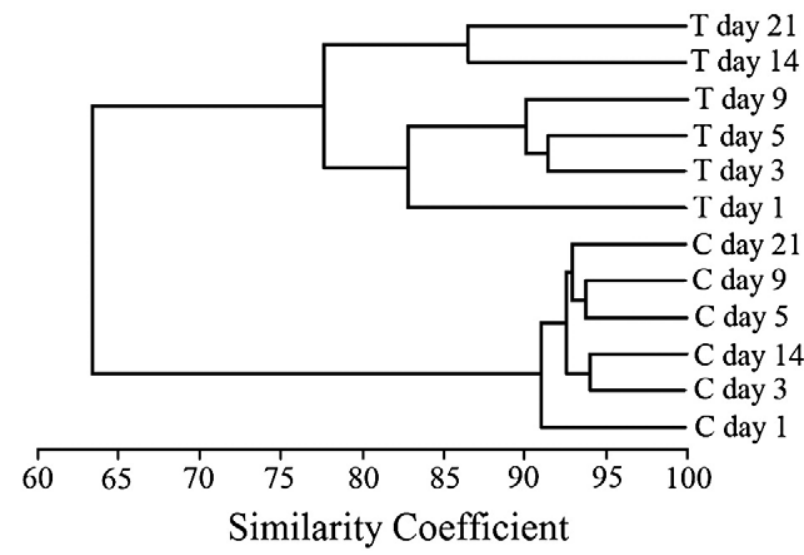

Fig. 4-Unweighted pair group method with arithmetic averages (UPGMA) cluster analysis of dice distance matrix calculated from DGGE banding patterns (based on presence/ absence and band weighting). 
Table 1-Microorganisms identified from predominant $16 S$ rDNA DGGE bands obtained from the phyllosphere of pepper leaves

\begin{tabular}{|c|c|c|c|}
\hline $\begin{array}{l}\text { DGGE } \\
\text { band }\end{array}$ & $\begin{array}{l}\text { Accession } \\
\text { number }\end{array}$ & Closest identity & $\begin{array}{c}\% \\
\text { Identity }\end{array}$ \\
\hline C1 & EU200325 & $\begin{array}{l}\text { Paenibacillus polymyxa } \\
\text { (EF643025) }\end{array}$ & 100 \\
\hline C2 & EU200326 & Acinetobacter sp. (AM778696) & 99 \\
\hline C3 & EU200327 & $\begin{array}{l}\text { Asticcacaulis biprosthecium } \\
\text { (AB014055) }\end{array}$ & 100 \\
\hline C4 & EU200328 & Clostridium sp. (AM884908) & 100 \\
\hline C5 & EU200329 & Bacterium RSB (AY822530) & 99 \\
\hline C6 & EU200330 & $\begin{array}{l}\text { Uncultured bacterium } \\
\text { (EF404509) }\end{array}$ & 98 \\
\hline C7 & EU200331 & $\begin{array}{l}\text { Unidentified eubacterium } \\
\text { (AJ232801) }\end{array}$ & 99 \\
\hline C8 & EU200332 & $\begin{array}{l}\text { Uncultured Lachnospiraceae } \\
\text { bacterium (EF706571) }\end{array}$ & 98 \\
\hline C9 & EU200333 & $\begin{array}{l}\text { Uncultured Acinetobacter sp. } \\
\text { (EU071491) }\end{array}$ & 99 \\
\hline C10 & EU200334 & $\begin{array}{l}\text { Bacteroidetes bacterium } \\
\text { (DQ195868) }\end{array}$ & 100 \\
\hline C11 & EU200335 & Enterococcus faecalis (AB244434) & 99 \\
\hline C12 & EU200336 & $\begin{array}{l}\text { Uncultured Bacilli bacterium } \\
\text { (EF706126) }\end{array}$ & 100 \\
\hline C13 & EU200337 & Pseudomonas putida (AM495258) & 100 \\
\hline C14 & EU200338 & $\begin{array}{l}\text { Pseudomonas rhodesiae } \\
\text { (AY043360) }\end{array}$ & 100 \\
\hline C15 & EU200339 & $\begin{array}{l}\text { Uncultured Pseudomonas sp. } \\
\text { (EU099607) }\end{array}$ & 100 \\
\hline C16 & EU200340 & $\begin{array}{l}\text { Uncultured bacterium } \\
\text { (EF379138) }\end{array}$ & 99 \\
\hline C17 & EU200341 & Pantoea dispersa (EU100012) & 97 \\
\hline C18 & EU200342 & $\begin{array}{l}\text { Acinetobacter calcoaceticus } \\
\text { (EF116074) }\end{array}$ & 98 \\
\hline C19 & EU200343 & $\begin{array}{l}\text { Uncultured bacterium } \\
\text { (AB286425) }\end{array}$ & 100 \\
\hline C20 & EU200344 & Pseudomonas sp. (EU099607) & 100 \\
\hline C21 & EU200345 & $\begin{array}{l}\text { Uncultured bacterium } \\
\text { (EF378189) }\end{array}$ & 99 \\
\hline C22 & EU200346 & Bacterium btn 7j-3 (AM113923) & 95 \\
\hline
\end{tabular}

Bacteroidetes, and $\gamma$-Proteobacteria. For the control sample, 12 bands were sequenced and consisted of eight members of the Firmicutes phylum (C1, C3, C4, C6, C8, C11, C12 and C19), 3 members of the $\gamma$-Proteobacteria phylum (C16, C17 and C20) and one member (C5) belonging to the Bacteroidetes phylum. A total of ten bands were identified from the pesticide treated samples consisting of seven members of the $\gamma$-Proteobacteria phylum (C2, C7, C9, C13, C14, C15 and C18) three members of the Bacteroidetes phylum (C10, C21 and C22).

\section{Discussion}

Microbial communities within the phyllosphere have important roles in aerial ecosystems of the plants. However, these communities are affected by various environmental conditions. For example, ultraviolet radiation has been shown to significantly alter the bacterial community structure within the maize phyllosphere (Kadivar and Stapleton, 2003), and rainfall wetting has been shown to change the phyllosphere community of ferns (Jackson et al., 2006). Microbial communities within the phyllo- sphere may also be affected by human influences. For example Green et al. (2006) showed the different effects that urea application to cherry leaf litter had on both bacterial and fungal communities. While there has also been a number of studies to assess the effects of pesticides on microbial communities in various environmental matrices, the study of pesticide effects on microbial communities specifically within the plant phyllosphere are relatively scarce. This study is the first to use cultureindependent methods of PLFA and PCR-DGGE to determine the

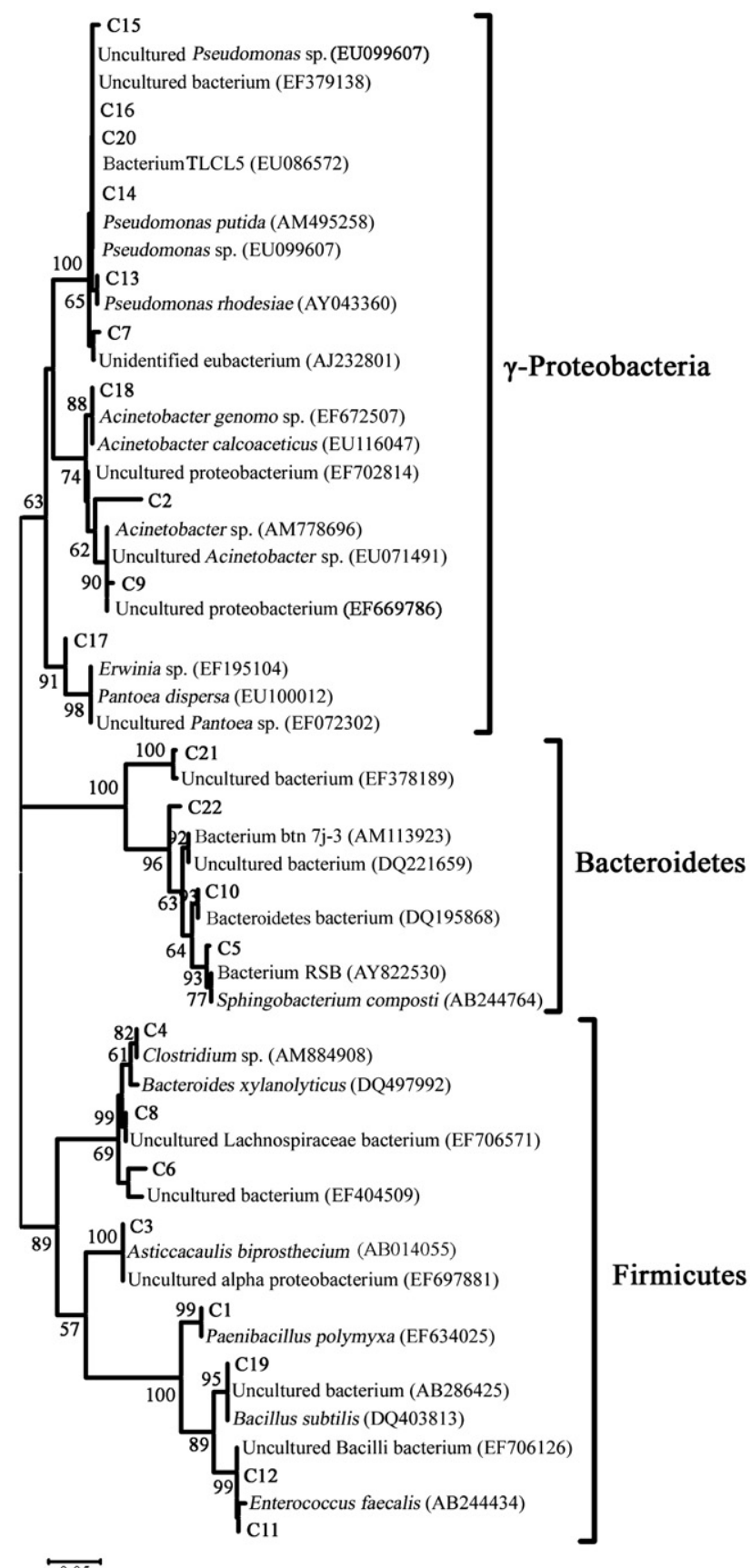

Fig. 5-Neighbor-joining analysis showing the phylogenic relationship of 16S rRNA gene sequences from excised DGGE bands to other related organisms. Band identities are described in Table 1. 
microbial changes that occur in the phyllosphere of pepper plant cultivars following the application of a synthetic pyrethroid pesticide cypermethrin solution.

Composite PLFA profiles provided an indication of microbial biomass, where total microbial biomass can be measured by summation of the mass of all detectable PLFAs (Ben-David et al., 2004). This, in turn, also provides an indication of the community structure within the phyllosphere. Total PLFAs, especially for the bacterial fraction, increased significantly following cypermethrin pesticide application compared to the associated controls (Fig. 1a). This may be explained by the fact that the cypermethrin pesticide and associated emulsifier or dimethylbenzene solvent was used as a carbon source by various bacterial groups (Grant et al., 2002; Jilani and Khan, 2006). Our PLFA-data for treated samples revealed a close association between unsaturated and cyclopropane PLFAs $(16: 1 \omega 7 \mathrm{t}, 18: 1 \omega 7$, cy17:0, cy19:0), which is indicative of Gram-negative bacteria.

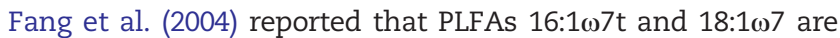
biomarkers of the pseudomonad group, where pseudomonads have been recently reported as degraders of cypermethrin (Grant et al., 2002; Grant and Betts, 2003; Jilani and Khan, 2006).

Alternatively, the increase in bacterial abundance following cypermethrin pesticide application may have been due to the negative effect of the pesticide upon fungal populations, resulting in a decrease of nutrient competition for the remaining bacterial populations, or due to the release of additional organic carbon as a result of insect decomposition following treatment. This phenomenon of bacterial communities increasing in abundance following pesticide treatment has also been shown in other studies. Diğrak and Kazanici (2001) reported that viable bacterial numbers were found to be higher than those of control groups during incubation in isofenphos-treated soil. In addition, Chinalia and Killham (2006) reported that bacterial biomass within sediment microcosms increased with inputs of 2,4Dichlorophenoxyacetic acid. However, there have also been studies to show that pesticide application results in a decrease in microbial community biomass, in addition to studies reporting no detectable change at all (Widenfalk et al., 2004; Widenfalk et al., 2008). This highlights the difficulty in anticipating the effect of pesticides upon the indigenous microbial communities, which is a function of not only the pesticide (and associated emulsifiers and solvents) but also the pesticide/microbe interaction, host/microbe interaction, microbe/microbe interactions, and also a range of environmental factors.

The changes induced by the cypermethrin pesticide application to the bacterial community composition of the pepper phyllosphere were also analyzed by PCR-DGGE. Several interesting differences between the pesticide treated and control samples were noted. Phylogenetic analysis also showed a shift in species composition with most of the species present only in the control samples (C1, C3, C4, C6, C8, C11, C12 and $\mathrm{C} 19)$ belonged to the Firmicutes, whereas the majority of the species detected only in the pesticide treated samples belonging to either Bacteroidetes or $\gamma$-Proteobacteria (Fig. 4). Over the time course of this study, the control samples displayed little change in banding profile but more significant changes were observed for the treated samples as highlighted in the dendrogram analyses (Fig. 5). Of most interest was the appearance of three novel bands (C13, C14 and C15) following the pesticide treatment as sequence analysis of these returned high similarities (98-100\%) to Pseudomonas sp. This may have occurred as the cypermethrin, emulsifier or dimethylbenzene solvent may have provided a carbon source for Pseudomonas sp. growth. This is in agreement with the PLFA results that also suggested the appearance of organisms belonging to the pseudomonad group, and the possibility that this group of organisms was involved in degradation of the chemicals in the pesticide EC here, resulting in an increase in bacterial abundance. After 14 days, the abundance of the bands C13, C14 and C15 decreased and may have done so due to exhaustion of the carbon source from the pesticide application. Further work is required to isolate the Pseudomonas sp. and subsequently confirm its degradation capacity.

In conclusion, this study has for the first time examined the microbial changes that occurred within the phyllosphere of pepper plant cultivars following the application of cypermethrin pesticide. Using two culture-independent techniques, PLFA and PCR-DGGE, results here suggested that application of cypermethrin pesticide (including the associated emulsifier and solvent solution) not only resulted in a significant change (PLFA PCAs and DGGE Monte Carlo permutation test) in bacterial community composition, but also resulted in an overall increase in total biomass within the phyllosphere. Future studies will investigate the influence of different pesticides upon the composition and structure of phyllosphere microbial communities for different plants. In turn, further understanding will be made regarding how the microbial communities may actually result in degradation of the pesticides.

\section{Acknowledgements}

This study was funded by the National Natural Science Foundation of China (No. 30600082), the "Knowledge Innovation" Program of Chinese Academy of Sciences (kzcx1-yw-0603) and the Beijing Municipal Commission of Education (20061D0502200295 and KM200811417006). We thank Prof Yehuda Cohen for his helpful suggestions.

\section{R E F E R E N C E S}

Amann RI, Ludwig W, Schleifer KH. Phylogenetic identification and in situ detection of individual microbial cells without cultivation. Microbiol Rev 1995;59:143-69.

Ben-David E, Holden PJ, Stone DJM, Harch BD, Foster LJ. The use of phospholipid fatty acid analysis to measure impact of acid rock drainage on microbial communities in sediments. Microbl Ecol 2004;48:300-15.

Burr MD, Clark SJ, Spear CR, Camper AK. Denaturing gradient gel electrophoresis can rapidly display the bacterial diversity contained in 16S rDNA clone libraries. Microbiol Ecol 2006;5:479-86.

Chinalia FA, Killham KS. 2,4-Dichlorophenoxyacetic acid (2,4-D) biodegradation in river sediments of Northeast-Scotland and its effect on the microbial communities (PLFA and DGGE). Chemosphere 2006;64:1675-83.

Diğrak M, Kazanici F. Effect of some organophosphorus insecticides on soil microorganisms. Turk J Biol 2001;25:51-8.

Fang J, Lovanh N, Alvarez PJJ. The use of isotopic and lipid analysis techniques linking toluene degradation to specific 
microorganisms: applications and limitations. Water Res 2004;38:2529-36.

Grant R, Betts WB. Biodegradation of the synthetic pyrethroid cypermethrin in used sheep dip. Lett Appl Microbiol 2003;36:173-6.

Grant R, Danill TJ, Betts WB. Isolation and identification of synthetic pyrethroid-degrading bacteria. J Appl Microbiol 2002;92:534-40.

Green H, Bengtsson M, Duval X, Pedersen HL, Hockenhull J, Larsen $\mathrm{J}$. Influence of urea on the cherry leaf spot pathogen, Blumeriella jaapii, and on microorganisms in decomposing cherry leaves. Soil Biol Biochem 2006;38:2731-42.

Henis Y, Bashan Y. Epiphytic survival of bacterial leaf pathogens. In: Fokkema NJ, Heuvel J, editors. Microbiology of the phyllosphere. Cambridge: Cambridge University Press; 1986. p. 252-68.

Hirano SS, Upper CD. Bacteria in the leaf ecosystem with emphasis on Pseudomonas syringae - a pathogen, ice nucleus, and epiphyte. Microbiol Mol Biol Rev 2000;64:624-53.

Jackson EF, Echlin HL, Jackson CR. Changes in the phyllosphere community of the resurrection fern, Polypodium polypodioides, associated with rainfall and wetting. FEMS Microbiol Ecol 2006;58:236-46.

Jilani S, Khan MA. Biodegradation of cypermethrin by Pseudomonas in a batch activated sludge process. Int J environ sci technol 2006;3:371-80.

Johansen A, Olsson S. Using phospholipid fatty acid technique to study short-term effects of the biological control agent Pseudomonas fluorescens DR54 on the microbial microbiota in barley rhizosphere. Microb Ecol 2005;49:272-81.

Kadivar H, Stapleton AE. Ultraviolet radiation alters maize phyllosphere bacterial diversity. Microb Ecol 2003;45:353-61.

Ko W, Lockwood JL. Conversion of DDT to DIDD in soil and the effect of these compounds on soil microorganisms. Can J Microbiol 1968;14:1069-73.

Krechel A, Faupel A, Hallmann J, Ulrich A, Berg G. Potato-associated bacteria and their antagonistic potential towards plant-pathogenic fungi and the plant-parasitic nematode Meloidogyne incognita (Kofoid \& White) Chitwood. Can J Microbiol 2002;48:772-86.

Krimm U, Abanda-Nkpwatt D, Schwab W, Schreiber L. Epiphytic microorganisms on strawberry plants (Fragaria ananassa cv. Elsanta): identification of bacterial isolates and analysis of their interaction with leaf surfaces. FEMS Microbiol Ecol 2005;53:483-92.

Kumar S, Tamura K, Nei M. MEGA3: integrated software for molecular evolutionary genetics analysis and sequence alignment. Brief Bioinform 2004;5:150-63.

Kvasnikov EI, Kliushnikova TM, Nagornaia SS. The nitrogen fixing ability of yeasts isolated from the rhizosphere and phyllosphere of plants. Mikrobiol Zh 1974;36:790-1.

Lal R, Saxena DM. Accumulation, metabolism, and effects of organochlorine insecticides on microorganisms. Microbiol Res 1982;46:95-127.

Lindow SE, Brandl MT. Microbiology of the phyllosphere. Appl Environ Microbiol 2003;69:1875-83.

Lindow SE, Leveau JH. Phyllosphere microbiology. Curr Opin Biotechnol 2002;13:238-43.

Morimoto S, Togami K, Ogawa N, Hasebe A, Fujii T. Analysis of a bacterial community in 3-chlorobenzoate-contaminated soil by PCR-DGGE targeting 16S rDNA and the benzoate 1,2-dioxygenase gene (benA). Microbes Environ 2005;20:151-9.

Murty MG. Phyllosphere of cotton as a habitat for diazotrophic microorganisms. Appl Environ Microbiol 1984;48:713-8.
O'Leary W, Wilkinson SG. Gram-positive bacteria. In: Ratledge C, Wilkinson SG, editors. Microbial lipids, vol. 1. London: Academic Press; 1988. p. 117-201.

$\emptyset$ vreås LFL, Daae FL, Torsvik V. Distribution of bacterioplankton in meromictic Lake Sælenvannet, as determined by denaturing gradient gel electrophoresis of PCR-amplified gene fragments coding for 16S rRNA. Appl Environ Microbiol 1997;63:3367-73.

Pandey P, Chauhan UK. Effects of pesticides (endo sulfan and quinal phos) on microbial community under controlled conditions. FASEB J 2007;21:791-2.

Patra AK, Le Roux X, Grayston SJ, Loiseau P, Louault F. Unraveling the effects of management regime and plant species on soil organic carbon and microbial phospholipid fatty acid profiles in grassland soils. Bioresour Technol 2008;99:3545-51.

Pennanen T, Liski J, Baath E, Kitunen VV, Uotila J, Westman CJ, et al. Structure of the microbial communities in coniferous forest soils in relation to site fertility and stand development stage. Microb Ecol 1999;38:168-79.

Ratcliff A, Busse MD, Shestak CJ. Changes in microbial community structure following herbicide (glyphosate) additions to forest soils. Appl Soil Ecol 2006;34:114-24.

Russell D, Chard J, McKinlay R. Effect of Bacillus thuringiensis and a pyrethroid insecticide on the leaf microflora of Brassica oleracea. Lett Appl Microbiol 1999;28:359-62.

Salonlus P. Effect of DDT and fenitrothion on forest soil microflora. J Econ Entomol 1972;65:1089-96.

Sandhu A, Halverson LJ, Beattie GA. Bacterial degradation of airborne phenol in the phyllosphere. Environ Microbiol 2007;9:383-92.

Schreiber L, Krimm U, Knoll D, Sayed M, Auling G, Kroppenstedt RM. Plant-microbe interactions: identification of epiphytic bacteria and their ability to alter leaf surface permeability. New Phytol 2005;166:589-94.

Vig K, Singh DK, Agarwal HC, Dhawan AK, Dureja P. Soil microorganisms in cotton fields sequentially treated with insecticides. Ecotoxicol Environ Saf 2008;69:263-76.

Walter M, Frampton CM, Boyd-Wilson KS, Harris-Virgin P, Waipara NW. Agrichemical impact on growth and survival of non-target apple phyllosphere microorganisms. Can J Microbiol 2007;53:45-55.

White DC, Stair J, Ringelberg DB. Quantitative comparisons of in situ microbial biodiversity by signature biomarker analysis. J Ind Microbiol Biotechnol 1996;17:185-96.

Widenfalk A, Bertilsson S, Sundh I, Goedkoop W. Effects of pesticides on community composition and activity of sediment microbeseresponses at various levels of microbial community organization. Environ Pollut 2008;152:576-84.

Widenfalk A, Goedkoop W, Svensson JM. Effects of the pesticides captan, deltamethrin, isoproturon, and pirimicarb on the microbial community of a freshwater sediment. Environ Toxicol Chem 2004;23:1920-7.

Wilkinson S. Gram-negative bacteria. In: Ratledge C, Wilkinson SG, editors. Microbial lipids, vol. 1. London: Academic Press; 1988. p. 299-448.

Yang CH, Crowley DE, Borneman J, Keen NT. Microbial phyllosphere populations are more complex than previously realized. Proc Natl Acad Sci U S A 2001;98:3889-94.

Zhang B, Bai Z, Hoefel D, Tang L, Yang Z, Zhuang G, et al. Assessing the impact of the biological control agent Bacillus thuringiensis on the indigenous microbial community within the pepper plant phyllosphere. FEMS Microbiol Lett 2008;284:102-8. 